\title{
CORRECTION
}

\section{Correction: Feasibility and tolerance of a robotic postural training to improve standing in a person with ambulatory spinal cord injury}

V. Santamaria, T. D. Luna (iD) and S. K. Agrawal

(c) The Author(s), under exclusive licence to International Spinal Cord Society 2021

Spinal Cord Series and Cases (2021)7:104; https://doi.org/10.1038/s41394-021-00467-6

Correction to: Spinal Cord Series and Cases https://doi.org/10.1038/ s41394-021-00454-x, published online 7 October 2021

In the original version of the article, Figure 6 was shown incorrectly. The figure should look like below. The original article has been corrected.

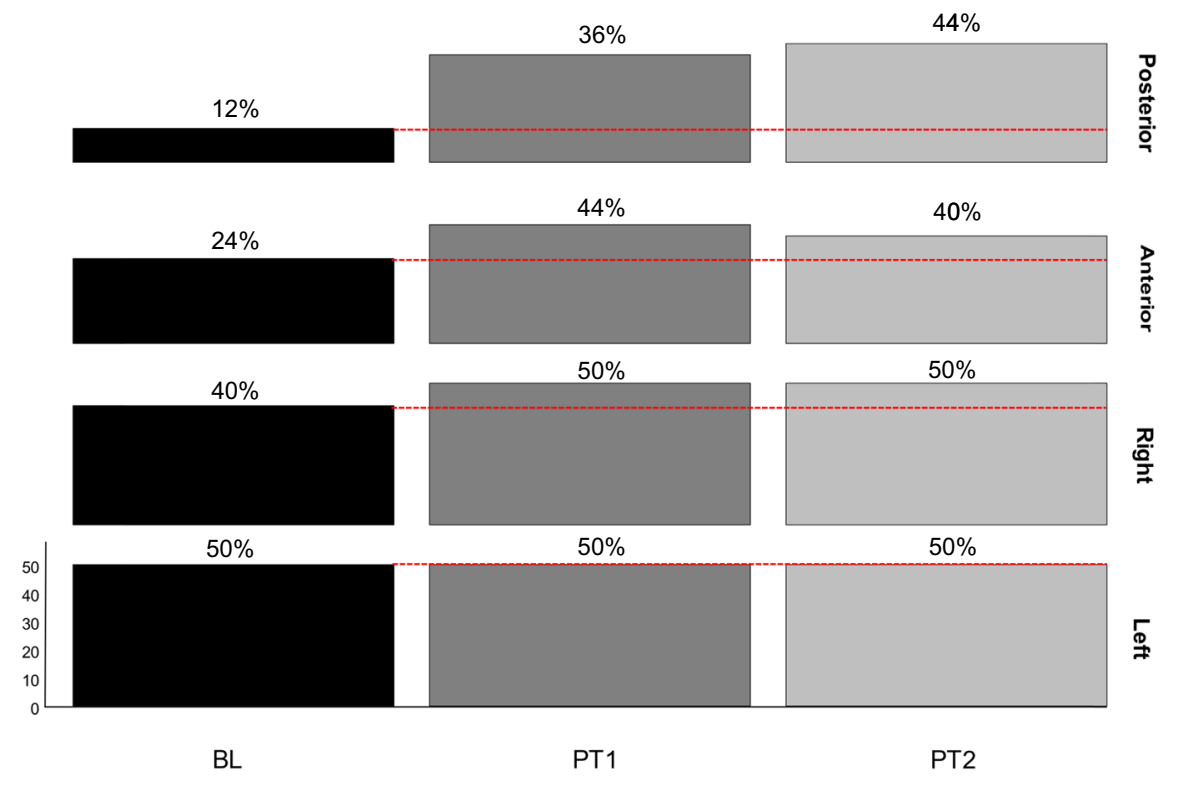

